\title{
Intestinal Stem Cell Imaging in Colorectal Cancer Screening
}

\author{
Moossavi $\mathrm{S}^{1}$, Ansari $\mathrm{R}^{1}$
}

\begin{abstract}
Colorectal cancer (CRC) is a common cancer and cause of cancer-related death worldwide. Although, the step-wise genetic alteration in the course of adenoma-carcinoma progression is well-understood, the mechanism of the tumour initiation and promotion is yet to be elucidated. Murine studies indicate that intestinal tumour originates from normal intestinal stem cells which acquire the oncogenic hits. It is plausible to consider the abnormality of the stem cell compartment as the earliest potentially detectable phenotypic change in the course of intestinal tumourigenesis. Hereby, it is hypothesised that imaging of the abnormal state of the intestinal stem cell compartment could potentially be integrated in CRC screening strategy.
\end{abstract}

Key Words: Molecular imaging, intestinal stem cell, early detection, colorectal cancer, Lgr5

\section{Introduction}

The feasibility of target detection in colorectal cancer (CRC) has been previously demonstrated in mice ${ }^{[1-4]}$. Nevertheless, the question to be addressed is what the best candidate molecule/cell is to target. Cancer is proposed to be the disease of the stem cell as the stem cells are the only longlived cells in a rapidly proliferating tissue such as the intestinal tract; the quality which makes them good candidates for accumulation of successive mutations required for the tumour evolution. In fact, stem cells are suggested to be responsible for tumour initiation, maintenance, and recurrence [5]. Intestinal stem cells (ISCs) are believed to reside in the crypts of Lieberkühn; which are invaginations of the epithelial layer into the stroma. The stem cells are responsible for the physiologic rapid cellular turnover of the intestinal epithelium and its regeneration after injury. Murine experiments have clearly shown that tumourigenic hits can only result in an intestinal tumour if they happen in the stem cell compartment and not the transient-amplifying region [6]. Adenomatous polyposis coli (APC) gene mutations that result in $\beta$-catenin activation, is the primary event in adenoma formation. It was observed that APC-driven adenoma originates either from a single or multiple APC-mutated Lgr5 ${ }^{+}$ISCs in mice ${ }^{[7]}$. In addition, constitutive activation of Wnt pathway was found to increase the number of stem cells and consequent transformation of them ${ }^{[8]}$. Recent evidence suggests differentiated intestinal epithelium can also be dedifferentiated and acquire stemness features upon constitutive Wnt pathway activation in chronic inflammatory milieu; which is capable of initiating the tumourigenesis process ${ }^{[9]}$.

Bjerknes suggests that the mutant colon stem cells expand faster than normal counterparts. This does not however, imply a higher rate of cell cycle in the mutant stem cell. It might be that more dormant stem cells return to the active cycling state compared to normal ${ }^{[10]}$. The first cellular alteration in familial adenomatous polyposis has been identified to be the 'proliferative shift' i.e. the upward migration of proliferative cells in an otherwise histologically normal mucosa. Boman et al. have employed computer simulation approach to understand the mechanism linking the existing $A P C$ mutation to cellular alterations in the crypt. It was noted that only an increase in the number of stem cells would consistently result in the upward shift of DNA synthesis. Moreover, $50 \%$ increase in the initial number of stem cells was sufficient to induce the phenomenon ${ }^{[11]}$. In human gut, murine ISC marker Lgr5 expression was found to be limited to the base of the crypt in normal mucosa, but increased and shifted upward in adenoma and CRC [12-14]. In adenoma, $\mathrm{Lgr5}^{+}$cells were observed at an increased number compared to normal crypts and were not located at the base of the crypt. Instead they were most frequently seen at the luminal surface [14]. The number of $\mathrm{Lgr5}^{+}$cells increases in parallel with adenoma-carcinoma progression and generally they migrate upward towards the luminal surface ${ }^{[15]}$. Overall, the evidence indicates expansion and upward shift of the $\mathrm{Lgr}^{+}$cell population in the course of CRC tumourigenesis.

Targeted intravital imaging of gastric, mammary, and glioblastoma cancer stem cells and normal stem cells in the hair follicle has been performed in mice ${ }^{[16-19]}$. Recently, Ritsma et al. have developed an abdominal imaging window (AIW) which could be surgically implanted in mice and be maintained in place for up to a month. Lgr5 ${ }^{+}$ISCs were successfully imaged in a single crypt over a few days through AIW ${ }^{[20]}$. Lgr5 $^{+}$ISCs were also imaged by two-photon microscope in Lgr5-eGFP ${ }^{+}$mice both in vivo and ex vivo. In vivo imaging was conducted following exteriorising a small intestinal loop on a glass slide. Lgr5 $^{+}$ISCs 
were readily visualized at the depth of $70 \mu \mathrm{m}$ in the small intestine and $217 \mu \mathrm{m}$ in the colon ${ }^{[21]}$.

Under normal circumstances only a limited number of ISCs exist at the base of the crypt. Increased number of ISCs and migration above the base of the crypt is an indication of stem cell expansion; which is speculated to be an early event in intestinal tumourigenesis. Therefore, targeted in vivo detection of ISCs and reconstruction of their position in relation to the base of the crypt could potentially be a powerful option for an integrative approach to CRC screening. To that end, a model is conceivable where a hypothetical line delineates the base of the crypt. Abnormal signal would then be defined as signal intensity more than the calculated average intensity i.e. hyperplasia of the stem cell and/or signal above the hypothetical boundary of the base of the crypt i.e. upward migration of the stem cell (Figure1).

Intravital ISC imaging faces major conceptual as well as technological challenges. The categorical identity of ISCs is still controversial. It is suggested that two functionally distinct groups of stem cells exist in the murine small intestine ${ }^{\text {[22]; }}$ the relevance of which to intestinal tumourigenesis is unknown. Moreover, ISCs are as yet not categorically identified and characterised in human. It is possible that ISCs have intercryptal and intracryptal heterogeneity; the relevance of which to intestinal tumourigenesis and the level of complexity imposed on intravital imaging are unknown.
Assuming that ISCs are known, they should be selectively labelled prior to the imaging. The nature and composition of the contrast agent need to be carefully decided to achieve high level of selective contrast as well as minimum toxicity and immunogenicity. In addition, the administration route of the contrast agent i.e. topical vs. intravenous needs to be decided. The choice of the imaging modality is of paramount importance. A high-resolution imaging technique with high penetration depth and sufficiently large field of view should be employed. It is best if it could be designed as an adjunct to the regular colonoscope as it should be able to scan the entire area of the colon mucosa. Image output should be readily understandable by the attending clinician. A scoring system should be designed to quantify and classify the result in order to integrate it within a multimodality screening strategy. However, in order to clinically apply this hypothesis, it is imperative to answer the following questions. Firstly, it should be determined whether stem cell compartment expansion happens in early CRC lesions in human. Secondly, the predictive value of the phenomenon needs to be calculated through longitudinal large scale investigation of colon samples. Long term follow-up is required to relate stem cell compartment expansion with the outcome as defined as developing CRC. Thirdly, in order to get an estimate for the false positive rate, it should be ascertained whether stem cell compartment is altered in conditions other than CRC. Finally, the likelihood of developing a stem cell compartment expansion event into CRC should be measured.
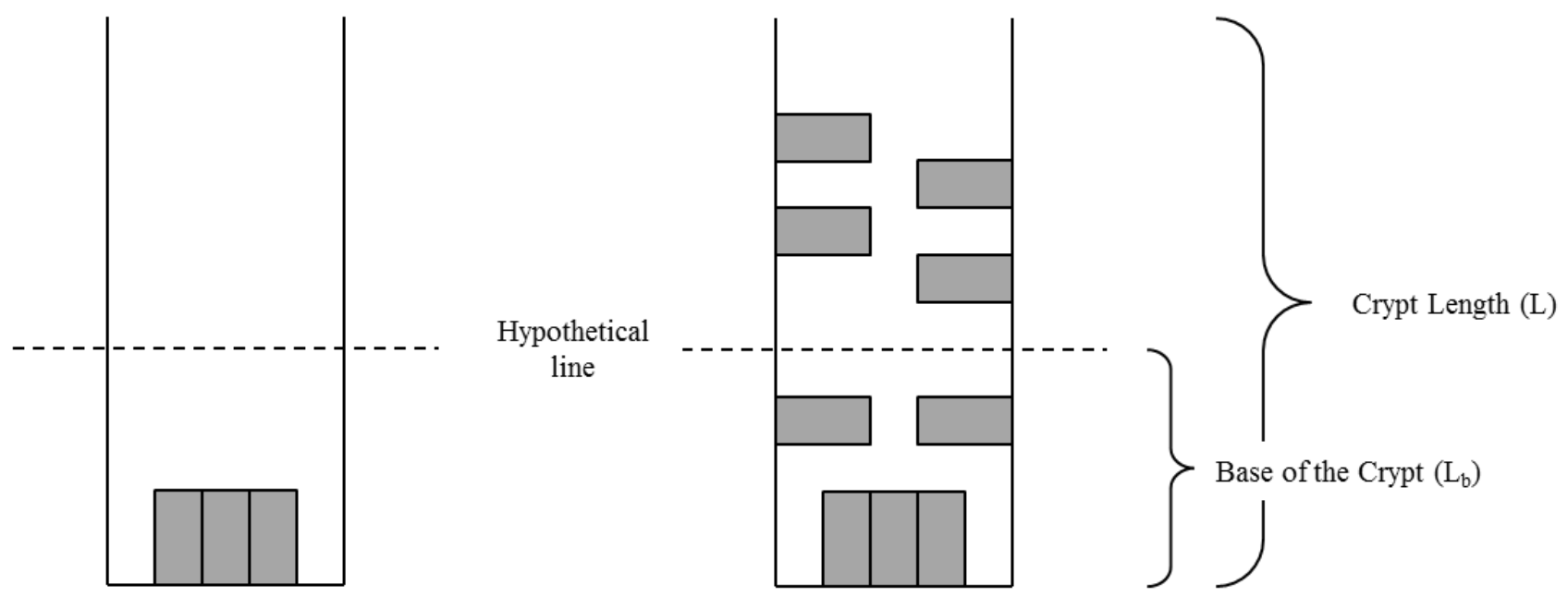

$$
\begin{gathered}
\text { Normal } \\
\mathrm{n} \leq \mathrm{s} \\
\mathrm{L}_{\mathrm{s}} \leq \mathrm{L}_{\mathrm{b}}
\end{gathered}
$$

Stem Cell Expansion

$\mathrm{n}>\mathrm{s}$

$\mathrm{L}_{\mathrm{s}}>\mathrm{L}_{\mathrm{b}}$

Figure 1. Schematic presentation of stem cell in the colon crypts. Under normal state, a limited number of stem cells exist at the base of the crypt. When stem cell compartment is expanded, the number of stem cells is increased and they migrate upward along the axis of the crypt. s, number of stem cells in normal condition; $n$, number of stem cells; $L$, length of the crypt; $L b$, length of the base of the crypt; $L s$, localization of the stem cell 


\section{References}

1. Goetz $M$, Ziebart $A$, Foersch $S$, Vieth $M$, Waldner $M J$, Delaney P, Galle PR, Neurath MF, Kiesslich R. In vivo molecular imaging of colorectal cancer with confocal endomicroscopy by targeting epidermal growth factor receptor. Gastroenterology. 2010; 138(2): 435-46.

2. Iftimia N, lyer AK, Hammer DX, Lue N, Mujat M, Pitman M, Ferguson RD, Amiji M. Fluorescence-guided optical coherence tomography imaging for colon cancer screening: a preliminary mouse study. Biomed Opt Express. 2012; 3(1): 178-191.

3. Goetz M, Hoetker MS, Diken M, Galle PR, Kiesslich R. In vivo molecular imaging with cetuximab, an anti-EGFR antibody, for prediction of response in xenograft models of human colorectal cancer. Endoscopy. 2013; 45(6): 469-77.

4. Foersch S, Neufert C, Neurath MF, Waldner MJ. Endomicroscopic Imaging of COX-2 Activity in Murine Sporadic and Colitis-Associated Colorectal Cancer. Diagn Ther Endosc. 2013; 2013:250641.

5. Zeki SS, Graham TA, Wright NA. Stem cells and their implications for colorectal cancer. Nat Rev Gastroenterol Hepatol. 2011; 8(2): 90-100.

6. Barker N, Ridgway RA, van Es $J H$, van de Wetering $M$, Begthel $H$, van den Born $M$, Danenberg $E$, Clarke $A R$, Sansom OJ, Clevers H. Crypt stem cells as the cells-of-origin of intestinal cancer. Nature. 2009; 457(7229): 608-11.

7. Schepers AG, Snippert HJ, Stange DE, van den Born M, van Es $J H$, van de Wetering $M$, Clevers $H$. Lineage Tracing Reveals Lgr5+ Stem Cell Activity in Mouse Intestinal Adenomas. Science. 2012; 337(6095): 730-35.

8. Zhu L, Gibson P, Currle DS, Tong Y, Richardson RJ, Bayazitov IT, Poppleton H, Zakharenko S, Ellison DW, Gilbertson RJ. Prominin 1 marks intestinal stem cells that are susceptible to neoplastic transformation. Nature. 2009; 457(7229): 603-07.

9. Schwitalla S, Fingerle AA, Cammareri $P$, Nebelsiek T, Göktuna SI, Ziegler PK, Canli O, Heijmans J, Huels DJ, Moreaux G, et al. Intestinal Tumorigenesis Initiated by Dedifferentiation and Acquisition of Stem-Cell-like Properties. Cell. 2013; 152(1-2): 1-14.

10. Bjerknes M. Expansion of mutant stem cell populations in the human colon. J Theor Biol. 1996; 178(4): 381-85.

11. Boman BM, Fields JZ, Bonham-carter O, Runquist OA. Computer Modeling Implicates Stem Cell Overproduction in Colon Cancer Initiation. Cancer Res. 2001; 61(23): 8408-11.

12. Uchida $H$, Yamazaki K, Fukuma M, Yamada T, Hayashida $\mathrm{T}$, Hasegawa $\mathrm{H}$, Kitajima M, Kitagawa $\mathrm{Y}$, Sakamoto M.
Overexpression of leucine-rich repeat-containing $G$ protein-coupled receptor 5 in colorectal cancer. Cancer Sci. 2010; 101(7): 1731-37.

13. Takahashi $H$, Ishii $H$, Nishida N, Takemasa I, Mizushima T, Ikeda M, Yokobori T, Mimori K, Yamamoto H, Sekimoto $\mathrm{M}$, et al. Significance of Lgr5(+ve) cancer stem cells in the colon and rectum. Ann Surg Oncol. 2011; 18(4): 1166-74.

14. Becker L, Huang Q, Mashimo $\mathrm{H}$. Immunostaining of Lgr5, an intestinal stem cell marker, in normal and premalignant human gastrointestinal tissue. ScientificWorldJournal. 2008; 18(4): 1168-76.

15. Fan XS, Wu HY, Yu HP, Zhou Q, Zhang YF, Huang Q. Expression of Lgr5 in human colorectal carcinogenesis and its potential correlation with beta-catenin. Int $\mathrm{J}$ Colorectal Dis. 2010; 25(5): 583-90.

16. Park J, Ku M, Kim E, Park Y, Hong Y, Haam S, Cheong JH, Park ES, Suh JS, Huh Y-M, et al. CD44-specific supramolecular hydrogels for fluorescence molecular imaging of stem-like gastric cancer cells. Integr Biol (Camb). 2013; 5(4): 669-72.

17. Zomer A, Ellenbroek SIJ, Ritsma L, Beerling E, Vrisekoop $\mathrm{N}$, Van Rheenen J. Brief report: intravital imaging of cancer stem cell plasticity in mammary tumors. Stem Cells. 2013; 31(3): 602-06.

18. Lathia JD, Gallagher J, Myers JT, Li M, Vasanji A, McLendon RE, Hjelmeland AB, Huang AY, Rich JN. Direct in vivo evidence for tumor propagation by glioblastoma cancer stem cells. PloS ONE. 2011; 6(9):e24807. doi:10.1371/journal.pone.0024807.

19. Rompolas P, Deschene ER, Zito G, Gonzalez DG, Saotome I, Haberman AM, Greco V. Live imaging of stem cell and progeny behaviour in physiological hair-follicle regeneration. Nature. 2012; 487(7408): 496-99.

20. Ritsma L, Steller EJ a, Ellenbroek SIJ, Kranenburg O, Borel Rinkes IHM, van Rheenen J. Surgical implantation of an abdominal imaging window for intravital microscopy. Nat Protoc. 2013; 8(3): 583-94.

21. Crosignani V, Dvornikov A, Aguilar JS, Stringari C, Edwards R, Mantulin WW, Grattona E. Deep tissue fluorescence imaging and in vivo biological applications. J Biomed Optics. 2012; 17(11): 116023.

22. Yan KS, Chia LA, Li X, Ootani A, Su J, Lee JY, Su N, Luo Y, Heilshorn SC, Amieva MR, et al. The intestinal stem cell markers Bmi1 and Lgr5 identify two functionally distinct populations. Proc Natl Acad Sci USA. 2012; 109(2): 46671.

\section{Potential Conflicts of Interests:}

None

\section{Abbreviations:}

APC: Adenomatous polyposis coli

AIW: Abdominal imaging window

CRC: Colorectal cancer

ISCs: Intestinal stem cells

\section{Correspondence to be addressed to:}

Shirin Moossavi, MD; Shariati Hospital, North Amirabad Ave., Tehran 14117, Iran; Tel: +98 21 82415154; Fax: +98 21 82415400; E-mail: shirin.moossavi@gmail.com 